\title{
Update on the British Columbia Thoracic Society's Annual Case Challenge
}

\author{
Francis LC Ervin MD FRCPC ${ }^{1}$, Ross E Chang MD FRCPC ${ }^{2}$
}

F or the past 14 years, the British Columbia (BC) Thoracic Society and BC Society of Allergy and Immunology have held an Annual Case Challenge and Continuing Medical Education program in partnership with GlaxoSmithKline Canada. This established program attracts an attendance comprising the majority of respirologists and allergists from across the province.

The annual program kicks off with an interhospital case challenge, whereby interesting and challenging cases are presented and discussed in a friendly yet competitive fashion. The winning team has their team name engraved on the "BCTS/BSCAI/GSK Case Challenge Cup" (BC Thoracic Society/British Columbia Society of Allergy and Immunology/GlaxoSmithKline Canada) - our 2003 winners were the Vancouver Island/Okanagan team, and in 2004, the Vancouver General Hospital team won this prestigious cup (see pictures).

The Saturday Continuing Medical Education program provides an excellent, MAINCERT accredited educational opportunity with a mixture of lecture and workshop sessions. In 2003, we were honoured to have Professor Peter Barnes, from the United Kingdom, as our keynote speaker, as well as several distinguished local faculty, including Dr Kevin Elwood, Dr Mark FitzGerald, Dr Robert Schellenberg and Dr Linda Vickars. This past year, Dr Denis O'Donnell from Queen's University in Kingston, Ontario was our keynote speaker, and other distinguished faculty included Dr Tony Bai, Dr Stephen Field, Dr Richard Finlay and Dr Murray Morrison.

This is a stellar educational program, and each year we strive to find new ways to continue to improve and build on the year before. We have included a few of the interesting cases from the past two years... and challenge you to develop your own case challenge.

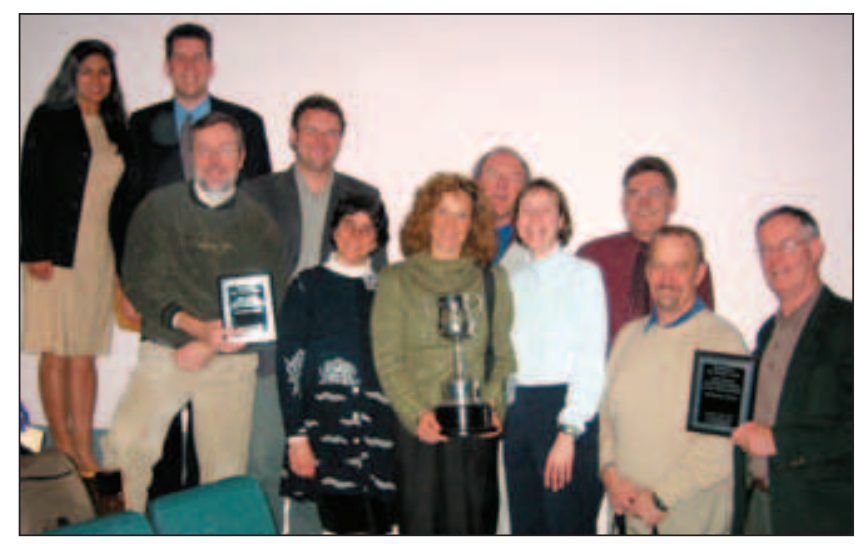

2003 Winners Vancouver Island/Okanagan Team (left to right): Subjit Dheenshaw (GlaxoSmithKline Canada [GSK]), Rick Bondaroff (GSK), and Dr Stephen Lundy, Dr Harold Yacyshyn, Dr Sarah Broader, Dr Shannon Walker, Dr Thomas Connolly, Dr Heather Clark, Mark Vukobrat (GSK), Dr Ian Waters and Dr Ross Anderton

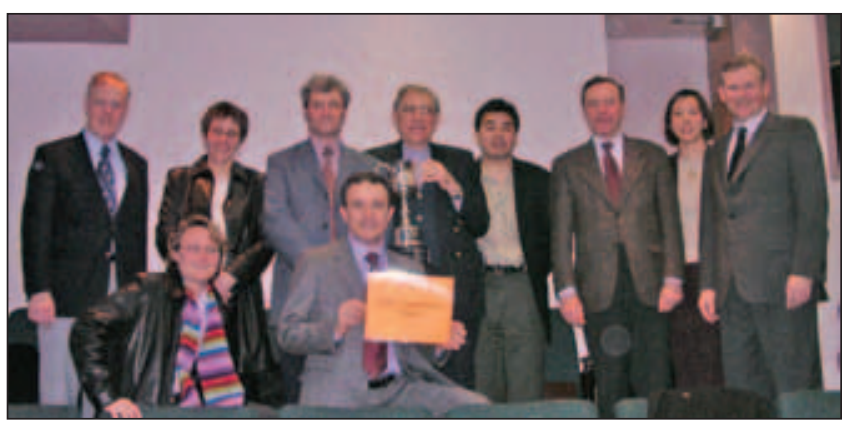

2004 Winners Vancouver General Hospital Team (left to right): Dr Donald Stark, Dr Victoria Cook, Dr Jennifer Wilson, Dr Frank Ryan, Dr Juan Ronco, Dr Raja Abboud, Dr Najib Ayas, Dr Paul Champion, Angela Lang (GlaxoSmithKline Canada) and John English

${ }^{1}$ Ridge Meadows Hospital, Maple Ridge; ${ }^{2}$ Burnaby Hospital, Burnaby, British Columbia

Correspondence: Dr Francis Ervin, e-mail flervin@telus.net; or Dr Ross Chang, e-mail rchang@telus.net 


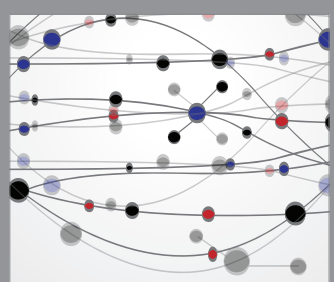

The Scientific World Journal
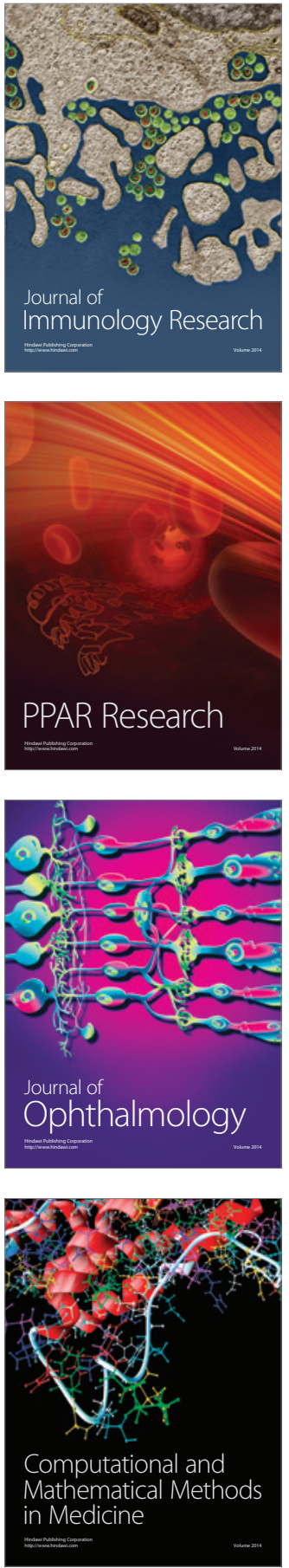

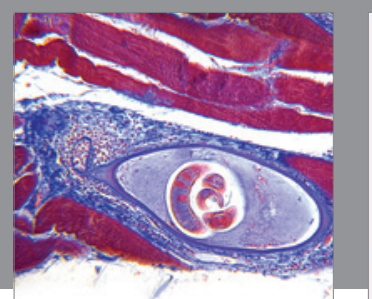

Gastroenterology Research and Practice

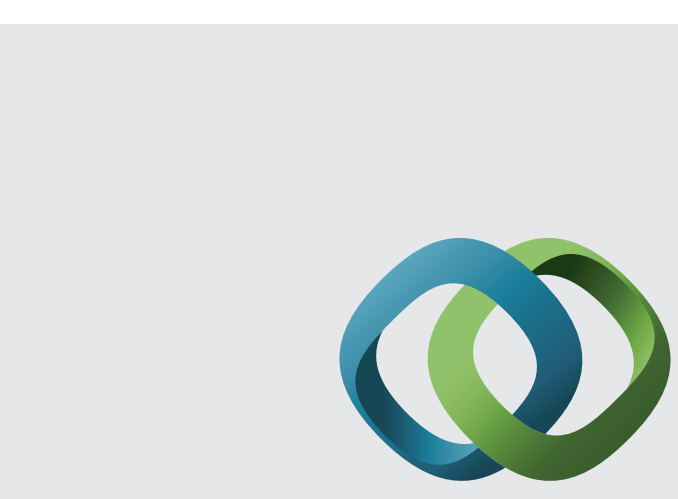

\section{Hindawi}

Submit your manuscripts at

http://www.hindawi.com
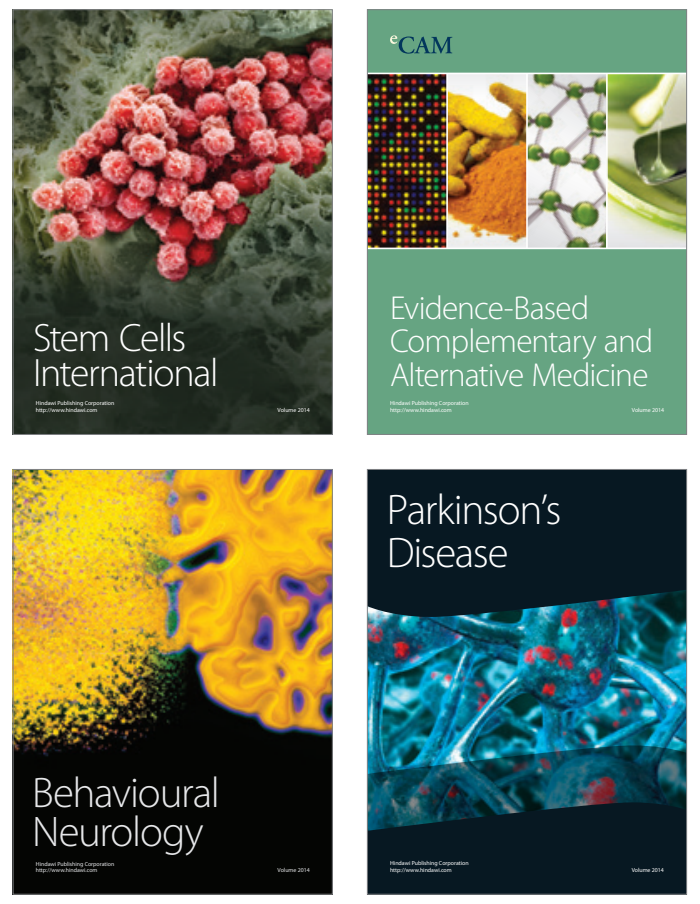
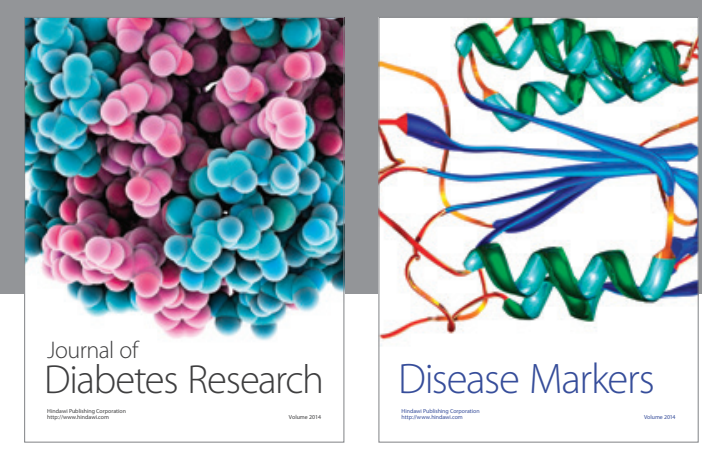

Disease Markers
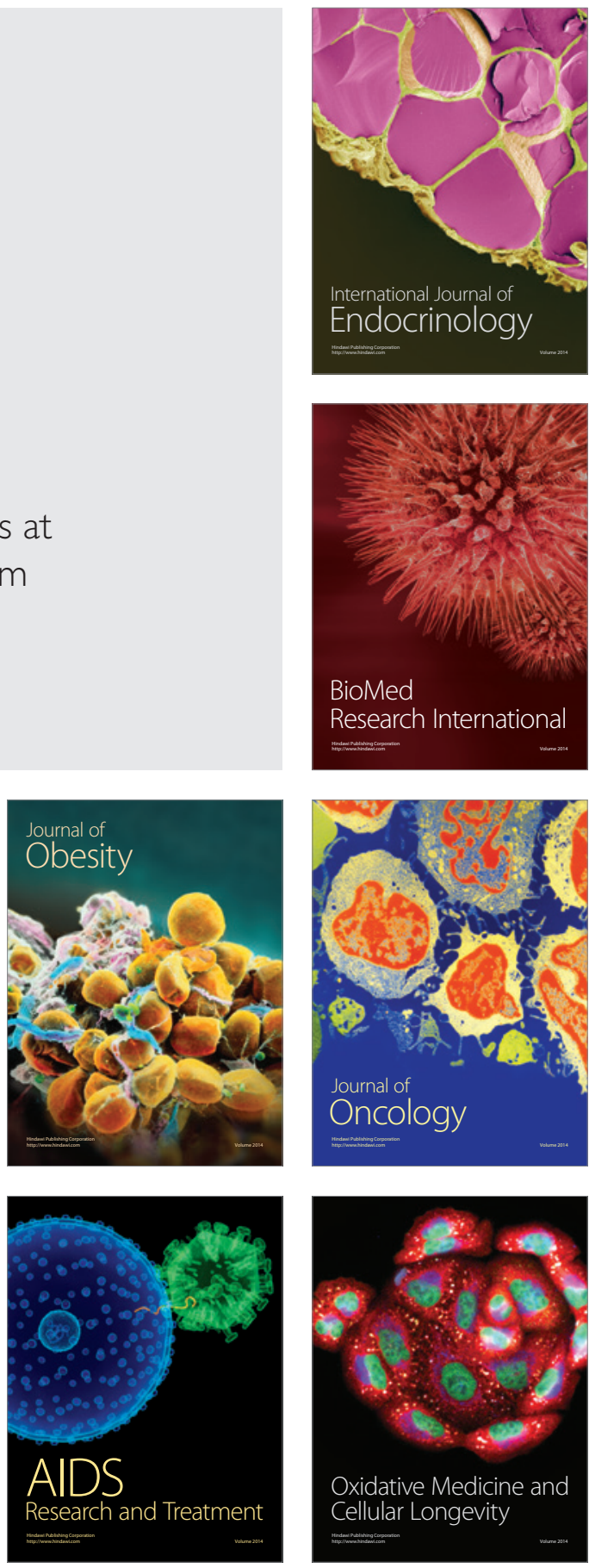